\title{
Social Adaptation of Students in a Multicultural Environment during Distance Learning
}

\author{
Iryna A. Soroka ${ }^{1, *}$ \\ ${ }^{1}$ Jindal Institute of Behavioural Sciences (JIBS), JGU, Sonipat, India \\ *Correspondence: Iryna A. Soroka, Jindal Institute of Behavioural Sciences (JIBS), JGU, Sonipat, Narela Road, Near \\ Jagdishpur Village, Sonipat, Haryana, 131001, India. E-mail: isoroka@jgu.edu.in
}

Received: December 9, 2021

Accepted: January 6, 2022 Online Published: January 17, 2022

doi:10.5430/jct.v11n1p208

URL: https://doi.org/10.5430/jct.v11n1p208

\begin{abstract}
The problem of social adaptation of students in a multicultural environment has always been a concern of pedagogical science. With the development of telecommunication technologies, educational institutions face with the issue of finding effective forms of interaction between students. The aim of the article is to theoretically and empirically develop an integrated concept of studying the resilience of foreign students in a multicultural environment during distance learning. Methods: survey, methods of remote collection and processing of information (GOOGLE Forms), Hardiness Scale (HS) developed by Kobasa and Maddi, statistical methods of data processing, methods of analysis of the reliability of survey. The correlation between adaptation and resilience of foreign students who participated in the study is $(\mathrm{r}=0.45 ; \mathrm{p}<0.01)$. In turn, the resilience index is $81.92 \%$. According to the study, students show high and medium rates of resilience during distance learning in the process of adaptation to a multicultural environment. It has been found that most students do not have difficulty adapting to distance learning due to the coronavirus pandemic (COVID-19). Thus, it was found that the process of adaptation of students in a multicultural environment during distance learning allowed maintaining a high rate of resilience, which indicates its effectiveness. Further research should be aimed at studying methods of increasing the level of students' social adaptation in the context of distance learning. These studies can be used by employees of higher education institutions to organize an adaptive learning process.
\end{abstract}

Keywords: social adaptation, educational process, multicultural environment, distance learning, resilience, multiculturalism

\section{Introduction}

At the current stage of higher education development, the creation of an innovative educational environment that is most favourable for the development of individual abilities, creative talents of students, shaping their professional competence and professional culture in general is a priority (Mardokhaev \& Varlamova, 2017). The current pandemic has led to a sudden shift to remote work and increased use of digital tools, which has launched a wide-ranging discussion of the impact of free access on the educational landscape, the nature of teaching and learning (Oleksy, Wnuk, Gambin, \& Łyś, 2021). Of course, the competencies of the $21^{\text {st }}$ century, which are related to the ability to respond flexibly to challenges and uncertainties, and to promote the initiatives of a sustainable society, is gaining significant attention. (Gordiienko-Mytrofanova, Pidchasov, Sauta, \& Kobzieva, 2018).

Distance learning has become the norm, not just one form of educational process in today's environment. So, the educational environment appropriately transformed in the cultural, managerial and pedagogical senses. The educational environment has formed signs of multiculturalism, turning them into a phenomenon thanks to distance learning and not only. The transformation of the educational environment under the influence of many socio-cultural challenges and global processes sets a precedent regarding the need for theoretical analysis of the process of social adaptation of students in a multicultural environment (Mittelmeier et al., 2019; Muscalu \& Muntean, 2013).

The multicultural competencies are being formed in the process of social adaptation; their main value is the pluralism of cultures. Multicultural education orients educational institutions to the cultural enrichment of all students, to the assimilation of programmes that contribute to the preservation and expansion of cultural pluralism. Awareness of the 
diversity, multiculturalism of the world and its integrity, interconnectedness, interdependence of cultures is the basic idea of the concept of multicultural education (Mirzaei \& Kadivarzare, 2014).

According to scholars, multiculturalism in education is cultural pluralism - the recognition of the equality of all ethnic and social groups that form a society, the inadmissibility of discrimination against people on the nationality-, religion-, gender- or age-based grounds. The basic principles of multicultural education are: dialogue and interaction of cultures; the principle of polarity of mastering the content of multicultural education; the principle of creative expediency of observance, preservation and creation of new cultural values (Toprak \& Kumtepe, 2017).

Education, on the one hand, should help people realize their roots and determine their place in the world, and on the other hand, instil respect for other cultures. The study of the culture of other peoples should contribute to the formation of human consciousness and behaviour, feelings of equality, dignity, spiritual culture of interethnic relations, to ensure cultural dialogue between representatives of different nationalities. In this regard, the multicultural environment aims to adapt foreign students to the new social conditions of an alien culture (Messias, Peseschkian \& Cagande, 2020).

The active introduction of the ideas of multiculturalism contributes to the formation of students' social readiness to cooperate with each other in polyethnic groups. We consider it reasonable to note that the problems of social adaptation in a multicultural environment were analysed by scientists in the $19^{\text {th }}-20^{\text {th }}$ centuries from different methodological positions (religious, dialectical-materialist, Freudian, existential and the like). All of them noted that the worldview and culture of the individual, on the one hand, are interrelated, and on the other - depend on the level and quality of education, as well as determine the social status and behaviour (Csikszentmihalyi, 2018).

In the early $20^{\text {th }}$ century, these problems were addressed by humanist educators in Germany. They interpreted multicultural education as a science that promotes the development of universal values in human consciousness and behaviour, and affirms the idea of the unity of the world. At the same time, representatives of the Bremen school Gurlitt, Hansberg, Charrelman - believed that the education mentioned above should also embrace "knowledge of world and national cultures, because multicultural education is a means of personal development, humanization, preparation for life in a democratic society" (Csikszentmihalyi, 2018).

In the 1970's and 1980's, D. Banks developed a different concept of multicultural education for American society. The basis of this concept is the interpretation of culture and the mission that any people undertake in society. The cross-cutting goal of multicultural education was the formation of intercultural competence among the young generation of citizens, and the ideal - "an open society built on the principles of meritocracy or personal merit" (Rizun \& Strzelecki, 2020). A multicultural society is a society of different opportunities for individuals from different ethnic, cultural and social groups (Messias, Peseschkian and Cagande, 2020). In such a society, individuals will be free to preserve their ethnic identity, to function effectively within the framework of general education in other cultures, too". The scientists believe that the content of education should reflect the culture of different ethnic groups and the heritage of the common American civilization (Gasanov, 1998; Peters et al., 2020).

The multicultural orientation of education must permeate all components of the educational process, and above all the content of the entire education. Multicultural content needs to be integrated into the subjects throughout the learning period (Bakracheva, 2019; Little and Blau, 2020).

Bilingual and multilingual education (native language, dominant language, foreign languages) plays a special role in the process of social adaptation in a multicultural environment during distance learning, which facilitates communication, assimilation of various cultural values, thinking styles, sensory-emotional perception, behaviour. Moreover, multicultural education as a mechanism for integrating domestic education into the international educational space is becoming increasingly important (Chykhantsova, 2020; Nuere \& de Miguel, 2020).

\subsection{Literature Review}

A large number of domestic and foreign scientists are puzzled by the issues of multicultural education and adaptation of students in the conditions of distance learning. Shaimukhametova (2019) pays attention in her work to satisfaction with the quality of life as a correlate of resilience of the individual in terms of innovative educational technologies. The author notes the high role of innovative technologies in the formation of resilience for most respondents. Ahlburg (2020) examines the impact of the pandemic on the work of UK universities, notes the need for measures for the social adaptation of students to new conditions, and offers social networks as such a tool. AI-Youbi et al. (2020) study the problems of adapting the educational process to the conditions of the pandemic at the University of King Abdulaziz. The paper notes a decreased level of student achievement not only due to changes in the form of education, but also with the emergence of social maladaptation. 
Chen, Basma, Ju and $\mathrm{Ng}$, (2020) raise the issue of opportunities and challenges of multicultural and international online education. The article emphasizes the importance of using social networks and messengers for intercultural dialogue in the context of distance learning. Social and cultural aspects of educational development are studied in the work of Egorychev, Mardokhaev and Ahtyan (2019). The authors emphasize the important role of Internet technologies in the formation of modern educational discourse. The issue of studying the opinions of students and teachers about the practice of distance learning during the coronavirus pandemic (COVID-19) is raised in the work of Hebebci, Bertiz and Alan (2020). The paper emphasizes the importance of social adaptation of students in the context of distance education as a component of the acquisition of professional competencies.

Huda, Mustafa and Mohamed (2021) examine the issue of the continuity of multicultural education in the interculturalist teacher discourse. The authors emphasize the need to understand multicultural resilience through the mutual acceptance of different cultures. Teachers' attitudes towards multicultural education are studied in Karacabey, Ozdere and Bozkus (2019). The authors point out the readiness of teachers to implement information technology to improve the climate of the university's multicultural environment.

The spatial scale, patterns and trends of positivity of SARS-CoV-2 pandemics in mass rapid antigen testing in Slovakia are studied in Bod'ová and Kollár (2021). The teacher's foreign language communicative competence as the basis of educational activities in a multicultural environment is studied in the work of Mardokhaev and Varlamova (2017). The paper emphasizes the high importance of acquiring communicative competencies in foreign language lessons for the formation of intercultural communication skills.

Although the topic is widely covered in the scientific literature, the study of the issue of social adaptation of students in a multicultural environment during distance learning is still relevant. This work deals with this issue.

\subsection{Problem Statement}

The study provides for carrying out a theoretical analysis of the issue of social adaptation of students of higher educational institutions in a multicultural environment in the context of distance learning, taking into account global, integration, transformation processes by studying the resilience indicators.

The object of the study is resilience as an indicator of social adaptation of students in a multicultural environment.

The subject of the study are psychological factors and mechanisms of development of the resilience of the student's personality during distance learning.

The aim of the study is to theoretically and empirically develop an integrated concept of studying the resilience of foreign students in a multicultural environment during distance learning, identifying factors, mechanisms of resilience and effective techniques for its development.

\section{Research objectives:}

1. Study the resilience of the individual as an indicator of social adaptation of students in a multicultural environment during distance learning and in-class.

2. Comparison of the well-being of foreign students during distance learning and in-class.

\section{Methods and Materials}

\subsection{Research Design}

The study was conducted in three stages:

Stage I of the experiment (2020) is summative. Experimental work at this stage included:

- study of the process of adaptation of students in a multicultural environment;

- preparation for the survey.

Stage II of the pedagogical experiment (December 2020 - March 2021) is formative. At the formative stage, the experimental work included:

- monitoring the progress of the study;

- analysis and processing of the results obtained during the experiment;

- summarizing the results of the study.

Stage III of the pedagogical experiment - (July 2021) - final. This stage of the experiment included the systematization and generalization of the results of experimental work, drawing conclusions of the study. So, the 
analysis of the scientific literature allows assuming that resilience is indirectly an indicator of social adaptation. We built a structural model of the relationship between the resilience and social adaptation of students in a multicultural environment based on this assumption (Figure 1).

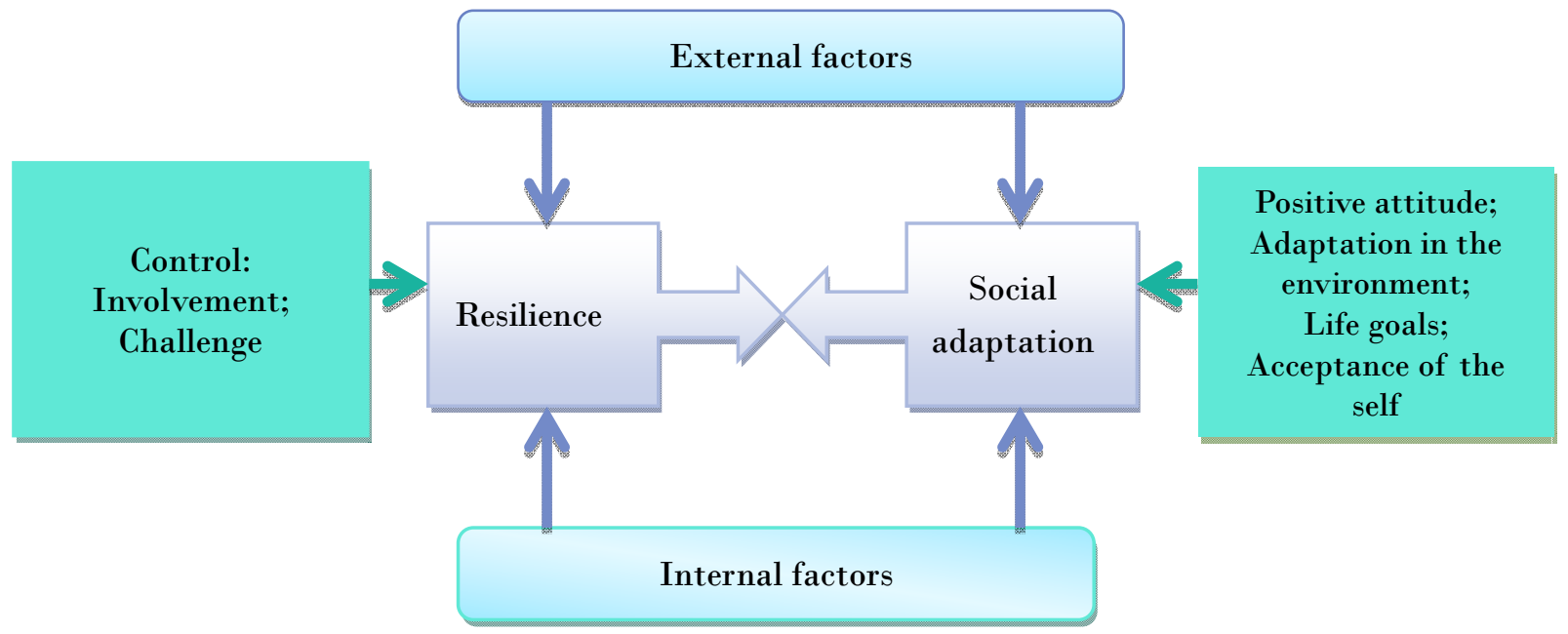

Figure 1. Structural Model of Relationships between Resilience and Social Adaptation of Students in a Multicultural Environment

That is, we can assume that increasing level of resilience will lead to increased levels of psychological adaptation of students in a multicultural environment. In other words, the higher the resilience of the individual, the more likely the level of his social adaptation will be high, and vice versa. The empirical study involved such psychodiagnostic techniques as:

- To diagnose the level of a person's resilience, we used the method developed by S. Maddi - the Hardiness Scale (HS). when considering the question of what psychological factors help to successfully overcome stress and reduce (or even prevent) internal tension in the process of social adaptation. The personality variable of resilience characterizes the measure of a person's ability to withstand a stressful situation, maintaining internal balance, and not reducing the success of activities. This construct was identified in the research when considering the psychological factors that help to successfully overcome stress and reduce (or even prevent) internal tension in the process of social adaptation.

The subjects are asked to answer 45 questions using answer options such as "no", "rather no more than yes", "rather yes than no", "yes". To calculate the points, the answers to the direct items correspond to points from 0 to 3 ("no" 0 points, "rather no than yes" -1 point, "rather yes than no" -2 points, "yes" -3 points), the answers to the reverse items are assigned points from 3 to 0 ("no" -3 points, "yes" - 0 points). The total resilience score and indicators for each of the three subscales are then summed. It should be noted that, in the absence of a clear division of the scale by levels, the following gradation was used in the calculation: for the Involvement scale: 0-29 points low level, 30-46 - medium level, 47-54 - high level; for the Control scale: 0-20 points - low level, 21-38 points - medium, 39-51 — high level; for the Challenge scale: 0-8 points — low level, 9-18 points — medium; 19-30 high level; for the general Resilience scale: 0-61 point — low level; 62-99 points — medium; 100-135 — high (Maddi \& Kobasa, 1984).

The results of the resilience test allow us to assess the ability and willingness of a person to act actively and flexibly in a situation of stress and difficulties or his/her vulnerability to stress. At the same time, resilience is a factor that contributes to the optimal experience of the situations of uncertainty and anxiety. Resilient beliefs create a kind of "immunity" to really difficult experiences. It is important that resilience affects not only the assessment of the situation, but also the person's activity in overcoming this situation.

Test time is 45 minutes.

All the tests listed above meet the psychometric requirements of reliability, discriminativeness, validity, and are provided with the norms for the student age group, for men and women (Chepeleva, 2010). 


\subsection{Sample}

We used random selection for sampling, because the representativeness of the sample is achieved by random selection, when each element of the general population has the same probability of being selected. The sample consisted of 1,075 respondents who agreed to take part in the survey by filling out an application on the Facebook page. This method of sampling satisfies the principles of randomness, reliability, ethics. The use of the social network allowed to significantly increase the number of respondents; this is why we can speak about the high reliability of the survey results. It was formed of foreign students of the $1^{\text {st }}$ to $4^{\text {th }}$ years of study at higher educational institutions of the faculties of humanities. The sample structure was as follows: $57 \%$ of respondents are women, $43 \%$ are men aged 17 to 30 . The sample variance was $\pm 6 \%$. In estimating the sample, we took into account how the sample was obtained and how many indicators of the general population "overlap" the sample indicators. The quantitative composition of the sample is sufficient to reflect the characteristics of the general population. Respondents were selected at the beginning of the work.

\subsection{Data Analysis}

Random errors of sample estimates are determined by the ratio of the variance of the random variable in the general population to the sample size. The following formula is used:

$$
\mathrm{n}=\frac{1}{\Delta^{2+\frac{1}{N}}}
$$

(where $\mathrm{N}$ - the volume of the general population, $\mathrm{n}$ - the sample size, $\Delta$ - the value of the allowable error)

The Pearson's parametric correlation $r$ was used to test hypotheses about the correlation between the variables. Factor analysis as a measuring method of structural modelling was used to test hypotheses about the number of factors and their loads in a hypothetical model of personality resilience.

\subsection{Statistical Processing}

The results of the empirical study were processed using a software for statistical data processing — SPSS Statistics 21.0 .

\subsection{Ethical Issues}

Research must comply with the principles of scientific nature, respect for the individual, integrity, professionalism. Since the study was conducted online, students were asked to answer questions honestly. The research results were processed and published with the student's consent.

\subsection{Research Limitations}

The study was limited in terms of sampling due to the pandemic. The sample was formed by attracting participants from among students of higher educational institutions on the Internet. This problem is compensated by a sufficient number of respondents to conduct a representative survey. As any research is a dynamic process and its course and outcome can differ significantly from the planned ones, we tried to avoid significant deviations, at least in terms of methodological procedures.

\section{Results}

We showed the specifics of the expression of the components of personality resilience in Figure 1. Analysing the figure, we can see that all three components, given the division of scales by S. Maddi's levels, are at a medium level. However, the expression of all three components of the resilience of the subjects is necessary for the optimal level of activity in difficult living conditions, as well as maintaining mental health. Table 1 shows the average values of the components of the subjects' resilience. 


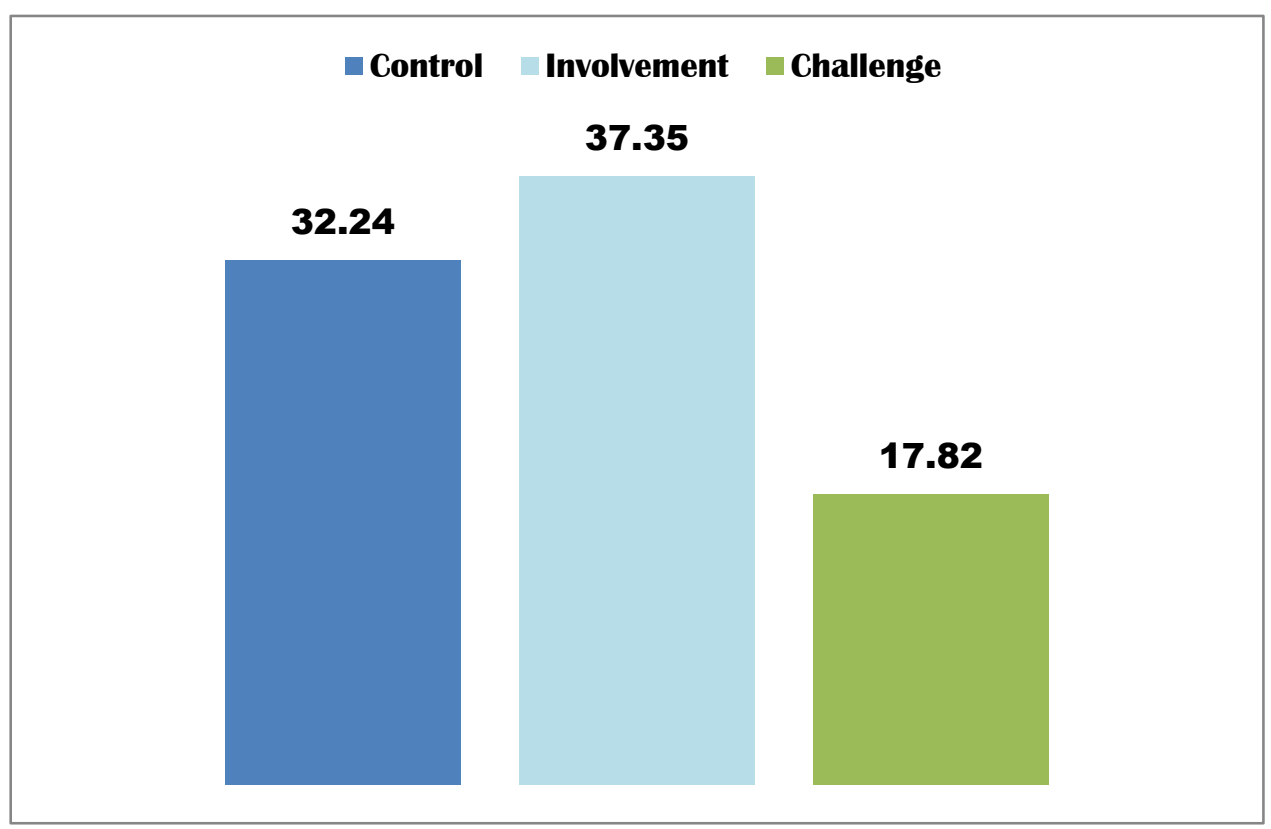

Figure 2. The Main Components of Students' Resilience

Table 1. The Average Value of the Main Components of the Students' Resilience

\begin{tabular}{lccc}
\hline & $\begin{array}{c}\text { Average value for distance } \\
\text { learning (\%) }\end{array}$ & $\begin{array}{c}\text { Average value for } \\
\text { in-class studies (\%) }\end{array}$ & $\boldsymbol{\Delta}$ \\
\hline Involvement & 34.42 & 41.40 & 6.98 \\
Control & 29.79 & 20.56 & 9.23 \\
Challenge & 17.72 & 18.01 & 4.802 \\
General resilience & 94.11 & 79.44 & 14.67 \\
\hline
\end{tabular}

According to the results obtained, we can say that the indicators of the components of resilience are expressed at the medium level and range within normal limits. Comparing the average values of resilience, it should be noted that all values are within the standard indicators. Its factors may, however, differ depending on the levels of resilience. The control indicator also differs: the distance learning indicator exceeds the in-class studies indicator by $9.23 \%$. The indicators of the Challenge criterion are almost the same. According to Table 1, the average value of the general resilience of students in distance learning is higher than that of students studying in-class by $14.67 \%$. And the rate of involvement for in-class studies is significantly higher than for distance learning (6.98\%). So, we see the general resilience of foreign students in distance learning higher than in students studying in-class. This is due to the low level of anxiety in the environment the students got used to. The Control indicator of students in distance learning exceeds that of the in-class studies, which helps students to more effectively find ways to solve emerging problems related to social adaptation in distance learning.

It should be noted that the study of the resilience of a self-determined person is one of the important areas in identifying the causes of actions, deeds, human activities, because resilience is seen as a set of components that help a person build a full life in difficult conditions. Analysing the results of the study, we hold the view that the resilience of foreign students in the process of social adaptation in a multicultural environment is manifested as an attitude to themselves, the world and the nature of interaction that empowers and motivates self-fulfilment, leadership, healthy thinking and behaviour; allows feeling meaningful and valuable enough to be fully involved in solving life problems, without paying attention to the adverse factors and changes.

So, resilience is one of the key parameters of individual ability to social adaptation. In general, every life situation sets the conditions for survival, adaptation, self-fulfilment, etc. Based on their meanings, values, meaningful attitudes, a person makes a certain choice, being in a certain activity determined by the action. The middle continuum includes people with a medium degree of resilience, which characterizes them as people who are interested enough in their activities, who have sufficient personal resources to overcome certain life problems and difficulties. Such people try 
to find ways to solve problems and control various life situations. Data containing the indicators of the correlation between general resilience and the level of adaptation are shown in Table 2.

Table 2. Correlation between General Resilience and Adaptation of Foreign Students in Distance Learning

\begin{tabular}{lllll}
\hline Scales & General resilience & Control & Involvement & Challenge \\
\hline Adaptation & $45^{* *}$ & $49^{* *}$ & $41^{* *}$ & $38^{* *}$ \\
\hline
\end{tabular}

Note: ${ }^{* *}$ Correlation at the level of 0.01 .

Let us note that the ability to adapt is an important factor in personal self-determination. Values on this scale $(\mathrm{r}=$ $0.45 ; \mathrm{p}<0.01)$ indicate that the subjects are characterized by sufficient success in overcoming adverse life difficulties. It should be noted that the person's adaptability characterizes him/her in terms of essential life principles, which he/she uses as a guide in life. Most respondents believe that they should be guided in life by their own values and show inner creativity, but at the same time think that this makes them vulnerable to difficult life situations and do not allow them to enjoy their life.

In accordance with the results of the Pearson correlation coefficient, a correlation was established between the indicators of involvement and adaptation $(\mathrm{r}=0.41 ; \mathrm{p}<0.01)$. This indicates the harmonious interaction of a person with the world around him/her, with the ability to perceive himself/herself as a significant and valuable person to be fully involved in solving life's problems, despite negative influences. Involvement promotes human self-actualization and a healthy way of thinking and behaving. Such a person is self-confident and enjoys his/her own activities. Correlation between adaptation and control is $(\mathrm{r}=0.49 ; \mathrm{p}<0.01)$. This suggests that a person is characterized by a willingness to perceive life events as challenges and trials. A person views life as a way of gaining experience, both positive and negative, for the purpose of his/her own development. And the pursuit of simple comfort and security is seen as impoverishing the life of the individual.

It should be noted that the person's resilience is associated with the ability to overcome various stresses, maintaining a high level of physical and psychological health, as well as optimism, self-efficacy, subjective satisfaction with one's life, ability to continuous personal self-development. It is a person's ability to overcome difficulties and obstacles, thus becoming stronger and more experienced. That is, the resilience of a self-determined person is a necessary resource that provides physical and mental health, effective adaptation in difficult life situations, as well as self-determination, that is, self-fulfilment in the world. The results of empirical research show that the students' resilience is the psychological background of their development, which creates conditions for them to achieve high results and a sense of satisfaction with life, as it allows them to coordinate their resources (abilities, personality traits, undiscovered opportunities, talents) for the organization of one's own life in general and the achievement of goals in particular.

\section{Discussion}

Let us note that the study of the levels of resilience of the individual revealed that it is generally within the statistical norm. Having identified the level of resilience in points, we counted the percentage of subjects with high, medium and low levels on the scales of resilience (involvement, control and challenge), as well as general resilience. Resilience in the process of adaptation is characterized by people's sociability, openness to the outside world, ease of expression, originality, uniqueness, both for themselves and others, the ability to accept themselves as they are, aversion to self-blame, a sense that life has meaning. These data contradict the research of Zhang, Wang, Yang, and Wang (2020), but are confirmed in the research of Oleksy et al. (2021), as well as Hong and Choi (2021). In their study, Zhang, et al. (2020) note the low students' ability of social adaptation during distance learning. Researchers explain this as a general psychological stress due to the introduction of quarantine measures, and a consequence of the violation of the natural socialization of students in the classroom environment of the university. Researchers do not consider the use of information technology an equivalent alternative.

Summarizing the data, we can say that the overall rate of resilience (compared to standard indicators) in the adaptation of students during the pandemic is medium. These findings are confirmed by studies of Rizun and Strzelecki (2020), which provide data on the results of resilience at $56 \%$, which is a lower line of the average result for the methodology described by the authors. They also note that such indicators of adaptation to a multicultural environment are characterized by a person's attitude to change, as well as his ability to use available internal 
resources that help manage them effectively, determine how well a person can cope with difficulties and changes he/she faces daily.

Research on the resilience of the individual during adaptation to a multicultural environment is one of the important areas in identifying the causes of actions, deeds, person's activities, so resilience is seen as a set of components that help individuals build a full life in difficult conditions. It is worth noting that the system of adaptation is formed in the process of human activity. This process is an essential part of socialization of the individual. In the structure of a mature developed personality, adaptation serves the function of long-term strategic life goals and motives of life, the realization of which is expressed in the contribution of the individual to culture, the creation of new forms of values. Consequently, the interaction of the individual and social communities is manifested in the transition from social to personal values (Seredenko \& Dolzhikova, 2009).

The correlation between adaptation and resilience of foreign students who participated in the study is ( $\mathrm{r}=0.45$; $\mathrm{p}<0.01$ ). These results contradict the research of Shcherbakova, Loseva, Misirov and Zhitnaya (2019), but confirm the conclusions of Marimuthu, Sankaranarayanan, Ali and Karuppiah (2021). Shcherbakova et al. (2019) note the level of adaptation at $(\mathrm{r}=0.52 ; \mathrm{p}<0.01)$ and link it with the influence of external factors, such as social pressure, the influence of parents. In turn, Marimuthu et al. (2021) show the high correlation between the level of resilience and the degree of adaptation of the individual to changes in the social environment.

Once again, we see resilience as an integrated consistent accomplishment which combines values that are important to the individual, determined by attitudes and beliefs about the world, the social environment and the place in it. Moreover, the development of such components of resilience as involvement, control and challenge contributes to the formation of positive thinking, as well as a positive worldview. It is worth noting that the system of personal values is formed in the process of human activity. This process is an essential part of the process of person's socialization. In the structure of a mature developed personality, values perform the function of long-term strategic life goals and motives of life, the realization of which is expressed in the individual's contribution to culture, the creation of new forms of values. Consequently, the interaction of the individual and social communities is manifested in the transition from social to personal values.

\section{Conclusions}

The generalization of the results of empirical research analysed in this work allowed us to conclude about the social adaptation of students in a multicultural environment during distance learning, and that the specifics of the expression of components of personality resilience is that resilience is an integrated consistent accomplishment. Moreover, the development of such components of resilience as involvement, control and challenge contributes to the formation of a positive attitude towards oneself and life events. That is, the expression of all three components of the resilience of the subjects is needed for the optimal level of activity in difficult living conditions, as well as maintaining mental health. So, international students showed a generally high ability to adapt in a multicultural environment. The level of resilience of respondents was $81.92 \%$, which is a high figure. The levels of involvement and control were $34.42 \%$ and 29.72 , respectively, which, of course, indicates the great potential of distance education in the process of social adaptation. But at this stage, such figures indicate the need to improve the climate of the multicultural environment under difficult quarantine restrictions to increase the level of the studied indicators. The Challenge rate is quite low and is $17.72 \%$.

It can be argued that each person has his/her own world of life, mediated by meanings and values, in the context of which a person makes his/her choices, makes decisions, builds his/her own life. Every life situation puts a person in conditions for survival, adaptation, self-realization, etc. Being in a certain activity, people make a certain choice based on their values, meanings, meaningful attitudes, which is determined by action. So, the correlation between the respondents' ability to adapt and resilience is $(\mathrm{r}=0.45 ; \mathrm{p}<0.01)$, indicating the success of foreign students in overcoming the negative impact of distance learning on the process of social adaptation. In turn, we can emphasize the very high correlation between the ability to adapt and control $(\mathrm{r}=0.49 ; \mathrm{p}<0.01)$, which indicates the readiness of foreign students to overcome the difficulties arising in the educational process.

Further research should be aimed at studying methods of increasing the level of students' social adaptation in the context of distance learning. These studies can be used by employees of higher education institutions to organize an adaptive learning process. 


\section{References}

Ahlburg, D. A. (2020). Covid-19 and UK universities. The Political Quarterly, 91(3), 649-654. https://doi.org/10.1111/1467-923X.12867

AI-Youbi, A. O., Al-Hayani, A., Bardesi, H. J., Basheri, M., Lytras, M. D., \& Aljohani, N. R. (2020). The King Abdulaziz University (KAU) pandemic framework: a methodological approach to leverage social media for the sustainable management of higher education in crisis. Sustainability, 12(11), 4367. https://doi.org/10.3390/su12114367

Bakracheva, M. (2019). Coping effects on life meaning, basic psychological needs and well-being. Psychology, 10(10), 1375-1395. https://doi.org/10.4236/psych.2019.1010090

Bod'ová, K., \& Kollár, R. (2021). Spatial scales, patterns, and positivity trends of SARS-CoV-2 pandemics in mass rapid antigen testing in Slovakia. PLoS ONE, 16(8), e0256669. https://doi.org/10.1371/journal.pone.0256669

Chen, S. Y., Basma, D., Ju, J., \& Ng, K. M. (2020). Opportunities and challenges of multicultural and international online education. Professional Counselor, 10(1), 120-132. https://doi.org/10.15241/syc.10.1.120

Chepeleva, N. V. (2010). Methodological foundations of personality research in the context of post-nonclassical psychology. Aktual'nì Problemi Psihologï̈, 6(2), 15-24.

Chykhantsova, O. A. (2020). A person's quality of life and features of its measurement. Insight: The Psychological Dimensions of Society, 4, 11-28. https://doi.org/10.32999/2663-970X/2020-4-1

Csikszentmihalyi, M. (2018). Finding flow: the psychology of engagement with everyday life (7th ed.). New York, NY: Basic Books.

Egorychev, A., Mardokhaev, L., \& Ahtyan, A. (2019). Social and cultural aspects of development of education. In: M. Vinogradova, A. C. Tankovic, \& G. Pavelin (Eds.), 45th International Scientific Conference on Economic and Social Development - XIX International Social Congress (ISC 2019) (pp. 542-549). Varazdin, Croatia: Varazdin Development and Entrepreneurship Agency.

Gasanov, Z. T. (1998). Education of a culture of interethnic communication: methodology, theory, practice. Makhachkala, Russian Federation: Epokha.

Gordiienko-Mytrofanova, I., Pidchasov, Y., Sauta, S., \& Kobzieva, I. (2018). The problem of sample representativeness for conducting experimental and broad psychological research. Psycholinguistics, 23(1), 11-46. https://doi.org/10.5281/zenodo. 1212360

Hebebci, M. T., Bertiz, Y., \& Alan, S. (2020). Investigation of Views of Students and Teachers on Distance Education Practices during the Coronavirus (COVID-19) Pandemic. International Journal of Technology in Education and Science, 4(4), 267-282. https://doi.org/10.46328/ijtes.v4i4.113

Hong, S., \& Choi, S-H (2021). The urban characteristics of high economic resilient neighborhoods during the COVID-19 pandemic: a case of Suwon, South Korea. Sustainability, 13(9), 4679. https://doi.org/10.3390/su13094679

Huda, M., Mustafa, M. C., \& Mohamed, A. K. (2021). Understanding of multicultural sustainability through mutual acceptance: voices from intercultural teachers' previous early education. Sustainability, 13(10), 5377. https://doi.org/10.3390/su13105377

Karacabey, M. F., Ozdere, M., \& Bozkus, K. (2019). The attitudes of teachers towards multicultural education. European Journal of Educational Research, 8(1), 383-393. https://doi.org/10.12973/eu-jer.8.1.383

Little, M. E., \& Blau, E. (2020). Social adaptation and climate mitigation through agrotourism: a case study of tourism in Mastatal, Costa Rica. Journal of Ecotourism, 19(2), 97-112. https://doi.org/10.1080/14724049.2019.1652305

Maddi, S. R., \& Kobasa, S. C. (1984). The hardy executive: Health under stress. Pacific Grove, CA: Brooks cole.

Mardokhaev, L., \& Varlamova, E. (2017). Foreign-language communicative competence of teacher as basis of educational activity in polycultural environment. Citise, 1(10).

Marimuthu, R., Sankaranarayanan, B., Ali, S. M., \& Karuppiah, K. (2021). Green recovery strategies for the mining industry of India: lessons learned from the COVID-19 pandemic. Journal of Asia Business Studies (Ahead of print). https://doi.org/10.1108/jabs-05-2021-0179 
Messias, E., Peseschkian, H., \& Cagande, C. (Eds.) (2020). Positive psychiatry, psychotherapy and psychology clinical applications. Cham, Switzerland: Springer International Publishing.

Mirzaei, F., \& Kadivarzare, H. (2014). Relationship between parenting styles and hardiness in high school students. Procedia-Social and Behavioral Sciences, 16, 3793-3797. https://doi.org/10.1016/j.sbspro.2014.01.843

Mittelmeier, J., Rienties, B., Rogaten, J., Gunter, A., \& Raghuram, P. (2019). Internationalisation at a Distance and at Home: Academic and social adjustment in a South African distance learning context. International Journal of Intercultural Relations, 72, 1-12. https://doi.org/10.1016/j.ijintrel.2019.06.001

Muscalu, E., \& Muntean, S. (2013). Motivation - a stimulating factor for increasing human resource management performance. Review of International Comparative Management, 14(2), 303-309.

Nuere, S., \& de Miguel, L. (2020). The digital/technological connection with covid-19: an unprecedented challenge in university teaching. Technology, Knowledge and Learning, 26, 931-943. https://doi.org/10.1007/s10758-020-09454-6

Oleksy, T., Wnuk, A., Gambin, M., \& Łyś, A. (2021). Dynamic relationships between different types of conspiracy theories about COVID-19 and protective behaviour: A four-wave panel study in Poland. Social Science \& Medicine, 280, 114028. https://doi.org/10.1016/j.socscimed.2021.114028

Peters, M. A., Wang, H., Ogunniran, M. O., Green, B., Omary Chunga, J., Atta Quainoo, E.,....\& Hayes, S. (2020). China's internationalized higher education during COVID-19: collective student autoethnography. Postdigital Science and Education, 2, 968-988. https://doi.org/10.1007/s42438-020-00128-1

Rizun, M., \& Strzelecki, A. (2020). Students' acceptance of the covid-19 impact on shifting higher education to distance learning in Poland. International Journal of Environmental Research and Public Health, 17(18), 6468. https://doi.org/10.3390/ijerph17186468

Seredenko, P. V., \& Dolzhikova, A. V. (2009). Methods of mathematical statistics in psychological and pedagogical research: Manual. Yuzhno-Sakhalinsk, Russian Federation: Sakhalin State University.

Shaimukhametova, S. F. (2019). Satisfaction with the quality of life as a correlate of the vitality of the individual. Azimuth of Scientific Research: Pedagogy and Psychology, 8/2(27), 406-408.

Shcherbakova, T., Loseva, I., Misirov, D., \& Zhitnaya I. (2019). Social competence and adaptation of the student in the polycultural educational system of higher education institution (on the material of the North Caucasus region). Science Almanac of Black Sea Region Countries, 2(18), 25-33.

Toprak, E., \& Kumtepe, E. G. (Eds.). (2017). Supporting multiculturalism in open and distance learning spaces. Hershey, PA: IGI Global.

Zhang, W., Wang, Y., Yang, L., \& Wang, C. (2020). Suspending classes without stopping learning: china's education emergency management policy in the COVID-19 outbreak. Journal of Risk and Financial Management, 13(3), 55. https://doi.org/10.3390/jrfm13030055

\section{Copyrights}

Copyright for this article is retained by the author(s), with first publication rights granted to the journal.

This is an open-access article distributed under the terms and conditions of the Creative Commons Attribution license (http://creativecommons.org/licenses/by/4.0/). 